\title{
Severe hemophagocytic lymphohistiocytosis in a melanoma patient treated with ipilimumab + nivolumab
}

\author{
Andrew Hantel ${ }^{1}$, Brooke Gabster ${ }^{2}$, Jason X. Cheng ${ }^{3}$, Harvey Golomb ${ }^{1}$ and Thomas F. Gajewski ${ }^{*}$
}

\begin{abstract}
Background: Treatment of metastatic melanoma patients with immune checkpoint inhibitors is an important standard of care. Side effects are due to immune activation, can affect virtually all organ systems, and are occasionally severe. Although hematologic toxicity has been reported, we present a case of hemophagocytic lymphohistiocytosis (HLH) due to immune checkpoint inhibitor therapy.

Case presentation: A patient with metastatic melanoma was treated with one course of ipilimumab + nivolumab and presented 3 weeks later with severe anemia and hyperferritinemia. A bone marrow biopsy revealed necrotic tumor cells, infiltrating $T$ cells, and hemophagocytosis. The patient was treated with high-dose steroids; 12 months later, the patient remains off all therapy and in complete remission of both HLH and metastatic melanoma.

Conclusions: The hemophagocytic syndromes are attributable to dysregulated immune activation and share pathophysiologic mechanisms with immune activation from checkpoint inhibitors. Increasing use of regimens that include immune checkpoint inhibition require vigilant monitoring for immune-activating side effects as they can occasionally be life threatening, as in this case of HLH.
\end{abstract}

Keywords: Melanoma, $\mathrm{HLH}$, Hemophagocytosis, Immune checkpoint, Checkpoint inhibitor

\section{Background}

Hemophagocytic lymphohistiocytosis (HLH) is a severe and life-threatening condition of excess immune activation, inflammatory response, and multi-organ failure [1]. The hemophagocytic syndromes (HPS), of which HLH is a part, are a group of syndromes that can be broadly divided into genetic and acquired etiologies [2]. Familial HLH (FLH), also referred to as primary or inherited, occurs as a result of a gene mutation in either one of the FLH loci or one of several loci responsible for immunodeficiency syndromes. The secondary HPS are comprised of acquired HLH and the pathophysiologically identical macrophage activation syndrome (MAS) [3]. HLH can stem from a variety of predisposing conditions of immune dysregulation such as malignancy, infection, or acquired immunodeficiency. The term MAS is used only when secondary HPS is a complication of

\footnotetext{
* Correspondence: tgajewsk@medicine.bsd.uchicago.edu

${ }^{1}$ Department of Medicine, Section of Hematology/Oncology, The University

of Chicago, 5841 S. Maryland Ave., MC2115, Chicago, IL 60637, USA

Full list of author information is available at the end of the article
}

rheumatologic disease, most commonly with systemic juvenile idiopathic arthritis, systemic lupus erythematosis, or adult onset Still's Disease [4]. HLH has been described, using various nomenclature, since a report 1939 by Scott and Smith [5] whereas MAS was first described in the literature in 1985 by Hadchouel [6].

The modern immunologic basis for HPS began to be uncovered in 1996 after the identification of cytotoxic deficiencies and common inflammatory patterns in patients with HLH [7]. This was followed shortly thereafter by the first description of perforin gene mutations in FLH by Stepp et al. [8]. In FLH, most known mutations result in protein deficiencies within the cytolytic secretory pathway. In this pathway, perforin and granzyme-containing granules are secreted into the synapses between cytolytic cells, namely cytotoxic $\mathrm{T}$ cells or natural killer cells, and their targets. Due to low cytolytic function, immune activation persists and hyperinflammation paradoxically results [9]. This pathophysiologic construct is clearer in FLH than in the acquired HLH, where abnormal T cell activation and inflammatory cytokine production, as well as paradoxical

(c) The Author(s). 2018 Open Access This article is distributed under the terms of the Creative Commons Attribution 4.0 International License (http://creativecommons.org/licenses/by/4.0/), which permits unrestricted use, distribution, and 
down-regulation of B cell function, Toll-like receptor expression and signaling, and apoptosis induction have also been noted to varying degrees $[10,11]$.

As a syndromic diagnosis, the classification of $\mathrm{HLH}$ was established by the Histiocyte Society in 1994 [12] and was most recently updated in their HLH-2004 guideline [3]. Unless molecular testing can establish a genetic basis for the syndrome, a constellation of eight criteria is used. To meet the diagnostic criteria, five of the following eight criteria must be met: fever $\left(>38^{\circ} \mathrm{C}\right)$; splenomegaly; cytopenias affecting two or more cell lines (hemoglobin $<9 \mathrm{~g} / \mathrm{dL}$, platelets $<100 \times 10^{3} / \mathrm{mL}$, neutrophils $<1 \times 10^{3} / \mathrm{mL}$ ), hypertriglyceridemia (fasting, > $265 \mathrm{mg} / \mathrm{dL})$ and/or hypofibrinogenemia $(<150 \mathrm{mg} / \mathrm{dL})$, hemophagocytosis in bone marrow, spleen, lymph nodes, or liver; low or absent NK cell activity; ferritin > $500 \mathrm{ng} / \mathrm{mL}$; elevated soluble CD25.

Immune checkpoint inhibition is the mainstay of modern treatment for metastatic melanoma [13]. Current checkpoint inhibitor therapy in melanoma is based on two immune targets: cytotoxic T-lymphocyte antigen 4 (CTLA-4) and the programmed cell death 1 (PD-1). CTLA-4 is a transmembrane protein expressed by activated $\mathrm{CD}^{+}$and $\mathrm{CD}^{+}{ }^{+} \mathrm{T}$-cells and negatively regulates their activation by antigen presenting cells [14]. PD-1 is a transmembrane protein expressed on activated $\mathrm{T}$ cells, $B$ cells, and NK cells that also inhibits their function upon engagement of the ligand, PD-ligand 1 (PDL-1), which is found across many tissue types including tumor cells [14]. PD-1/PDL-1 interactions have been associated with $\mathrm{T}$ cell dysfunction in the tumor microenvironment, and also can play a role in the conversion of conventional $\mathrm{T}$ cells to regulatory $\mathrm{T}$-cells [15]. Antibodies against these targets have been shown to improve $\mathrm{T}$ cell activation and exert anti-tumor immunity in multiple preclinical models, including augmented cytolytic $\mathrm{T}$ cell activity [16]. Notably, these are the characteristics of immune responses that appear to be dysregulated in HLH.

Antibodies targeting CLTA-4 and PD-1, ipilimumab and nivolumab or pembrolizumab, have been independently shown to improve overall survival in unresectable melanoma [17-19]. More recently, their use in combination was found to improve response rates, performance free survival, and overall survival in the first line setting [20]. The Checkmate-067 Trial studied the combination of nivolumab and ipilimumab versus either nivolumab or ipilimumab as single agents. In a recently updated analysis, the trial showed objective response rates of $58.9,44.6$, and $19 \%$, median progression-free survival of 11.7 months, 6.9 months, and 2.9 months, and 3 year overall survival rates of 58,52 , and $34 \%$ for nivolumab plus ipilimumab, nivolumab, and ipilimumab, respectively. Notable within the original report of the Checkmate-067 Trial was the increased incidence of grade 3 or 4 side effects in the combination treatment group at $58.5 \%$ vs $20.8 \%$ with nivolumab and $27.7 \%$ with ipilimumab [21]. Additionally, close to $40 \%$ of patients on combination therapy stopped treatment due to adverse events.

There appears to be significant overlap between the dysregulated immune activation underlying $\mathrm{HLH}$ and the immune activating toxicities seen with immune checkpoint inhibitors. Below, we present our case of HLH in the setting of metastatic melanoma treated with combination checkpoint inhibition.

\section{Case presentation}

A 35-year-old woman was evaluated in clinic with progressive fatigue, pre-syncope, upper respiratory symptoms, pallor, and low-grade fevers over the preceding week. She had been diagnosed with locally advanced malignant melanoma of her left upper extremity 10 months prior, in March 2016. The patient had undergone a complete surgical resection with sentinel lymph node biopsy, which showed melanoma with a Breslow depth of $2.2 \mathrm{~mm}$. One of three sentinel nodes was positive for metastasis and the tumor was negative for BRAF or KIT mutations. This resection was followed by a complete level three axillary lymph node dissection, which was negative for further metastasis. She then received $4 \mathrm{cy}$ cles of adjuvant ipilimumab, which was complicated by panhypopituitarism. Two months after completing adjuvant treatment she reported a dry cough and fatigue. Computed tomography showed widespread metastatic disease in the bilateral lungs and axial skeleton, including a sternal mass with soft tissue extension. Three weeks before presentation she was given her first doses of combination immunotherapy with ipilimumab and nivolumab.

On examination, she was pale and slightly jaundiced. Cardiac exam revealed a regular, tachycardic rhythm and her lungs were clear to auscultation. She had a benign abdominal exam but exhibited palpable splenomegaly below the left costal margin. There were no ecchymoses or petechiae. Her heart rate was $121 \mathrm{BPM}$ and her blood pressure was $82 / 45 \mathrm{mmHg}$. Her hematologic work up revealed a hemoglobin of $2.9 \mathrm{mg} / \mathrm{dL}$ and a platelet count of $79 \times$ $10^{\wedge} 3 / \mathrm{uL}$, both decreased from values of $8.0 \mathrm{mg} / \mathrm{dL}$ and $119 \times 10^{\wedge} 3 /$ uL, respectively, 2 weeks prior. Her bilirubin was elevated to $2.9 \mathrm{mg} / \mathrm{dL}$, of which $1.7 \mathrm{mg} / \mathrm{dL}$ was unconjugated. Her prothrombin and partial prothrombin times were normal and the patient denied any recent history of bleeding. She was given intravenous fluid boluses and admitted to the hospital for further work-up.

In the hospital, her hemoglobin level increased to $7.0 \mathrm{mg} / \mathrm{dL}$ after being transfused with 4 units of packed red blood cells. It decreased again below $7.0 \mathrm{mg} / \mathrm{dL}$ on hospital days two and three, prompting two more units of 
blood. Further laboratory testing revealed a lactate dehydrogenase level of $1029 \mathrm{U} / \mathrm{L}$, a C-reactive protein of $202 \mathrm{mg} / \mathrm{L}$, and a haptoglobin of $<20 \mathrm{mg} / \mathrm{dL}$. Her direct Coombs test was negative and glucose-6-phosphate dehydrogenase level was normal. Bilirubin increased to $8.5 \mathrm{mg} / \mathrm{dL}$, of which $5.4 \mathrm{mg} / \mathrm{dL}$ was conjugated. Her ferritin level was elevated to $5474 \mathrm{ng} / \mathrm{mL}$ and fasting triglyceride level was $336 \mathrm{mg} / \mathrm{dL}$. The reticulocyte production index was 0.6. An ADAMTS13 function was normal and an inhibitor was not found. Her cortisol level was $42.7 \mu \mathrm{g} /$ $\mathrm{dL}$, thyrotropin was reduced at $0.07 \mathrm{mcU} / \mathrm{mL}$, and free thyroxine was $1.65 \mathrm{ng} / \mathrm{dL}$. An infectious work up, including blood and urine cultures, parvovirus, EBV, and CMV serology was negative. An MRI of her liver showed a stable hemangioma and stable metastatic deposits were noted in the incidentally visible lung. Trends in the patient's laboratory values can be seen in Fig. 1.

A hematopathology review of the peripheral blood showed a marked reduction in red blood cells with the remainder displaying spherocytosis, ansiopoikilcytosis, and rare teardrop forms. The granulocytes and lymphocytes appeared mature and normal. A bone marrow biopsy of her posterior iliac crest was performed. The core biopsy sections (Fig. 2) revealed a hypercellular bone marrow (approximately $85 \%$ of total area) with large sections of tumor cell necrosis. Occasional positive S100 and Melan A immunostains were noted within the dead tumor debris. $\mathrm{CD}^{+} \mathrm{T}$ cells were abundant, the majority of which were $\mathrm{CD}^{+}$(Fig. 2c). Moderate serous atrophy and MF-2 fibrosis was noted on reticulin staining. Unexpectedly, it also revealed increased histiocytes throughout the marrow with active hemophagocytosis (Fig. 2b, blue arrows).
Soluble CD25 levels were significantly elevated at $2840 \mathrm{U} /$ $\mathrm{mL}$.

Given these laboratory results, in combination with the patient's clinical signs and symptoms, HLH was considered. The patient met HLH-2004 criteria with her splenomegaly, cytopenias, hypertriglyceridemia, hemophagocytosis, elevated ferritin, and elevated soluble CD25 levels establishing the diagnosis. The patient was started on $1.5 \mathrm{mg} / \mathrm{kg}$ of methylprednisone every 8 hours on hospital day four and her hemoglobin began to improve; further transfusions were not required. She was monitored in the hospital for 4 days and the steroid dose was decreased to $1 \mathrm{mg} / \mathrm{kg}$ of oral prednisone. On discharge, her hemoglobin had increased to $9.1 \mathrm{mg} / \mathrm{dL}$ without further transfusion. The use of additional treatment, per HLH-2004 guidelines, was considered but was decided against given her marked improvement and with consideration of the etiology of her presentation.

Over the course of the next 2 months, her bilirubin decreased to $0.2 \mathrm{mg} / \mathrm{dL}$, ferritin to 651 , CRP to $<3 \mathrm{mg} / \mathrm{L}$, and lactate dehydrogenase to $253 \mathrm{U} / \mathrm{L}$ (Fig. 1). She remained on high-dose steroids for 1 month before being tapered slowly down to her prior replacement dose regimen for panhypopituitarism. On a follow up clinic visits in 2017, the hemoglobin was maintained above $14 \mathrm{mg} / \mathrm{dL}$ and a computed tomographic scans revealed a resolution of both her previous metastatic lung nodules and sternal mass. A repeat bone marrow biopsy was performed due to a residual abnormal bone marrow intensity noted by $\mathrm{CT}$ imaging. This demonstrated focal bone marrow remodeling with trilineage hematopoiesis, no hemophagocytic activity, and no morphologic or immunohistochemical

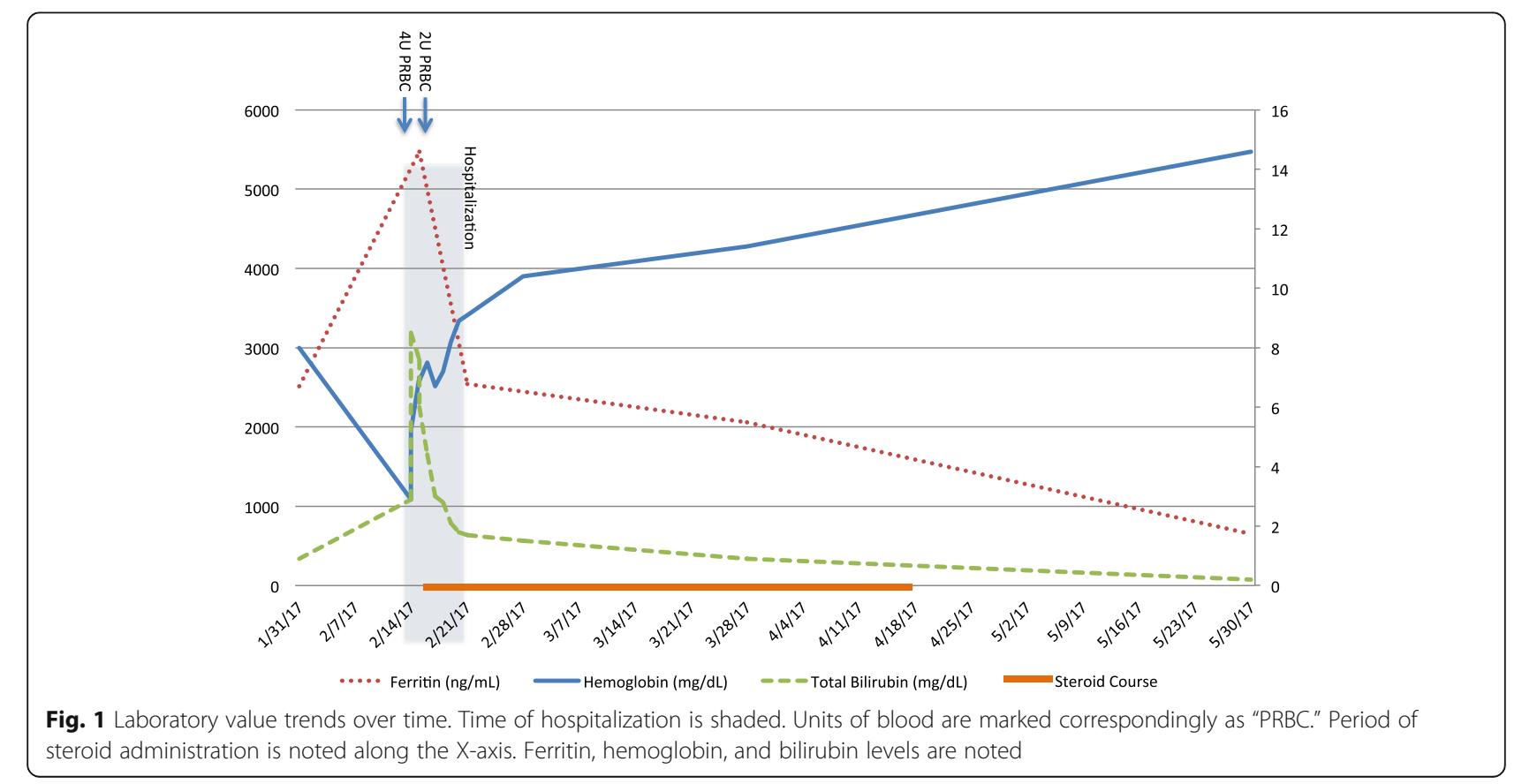



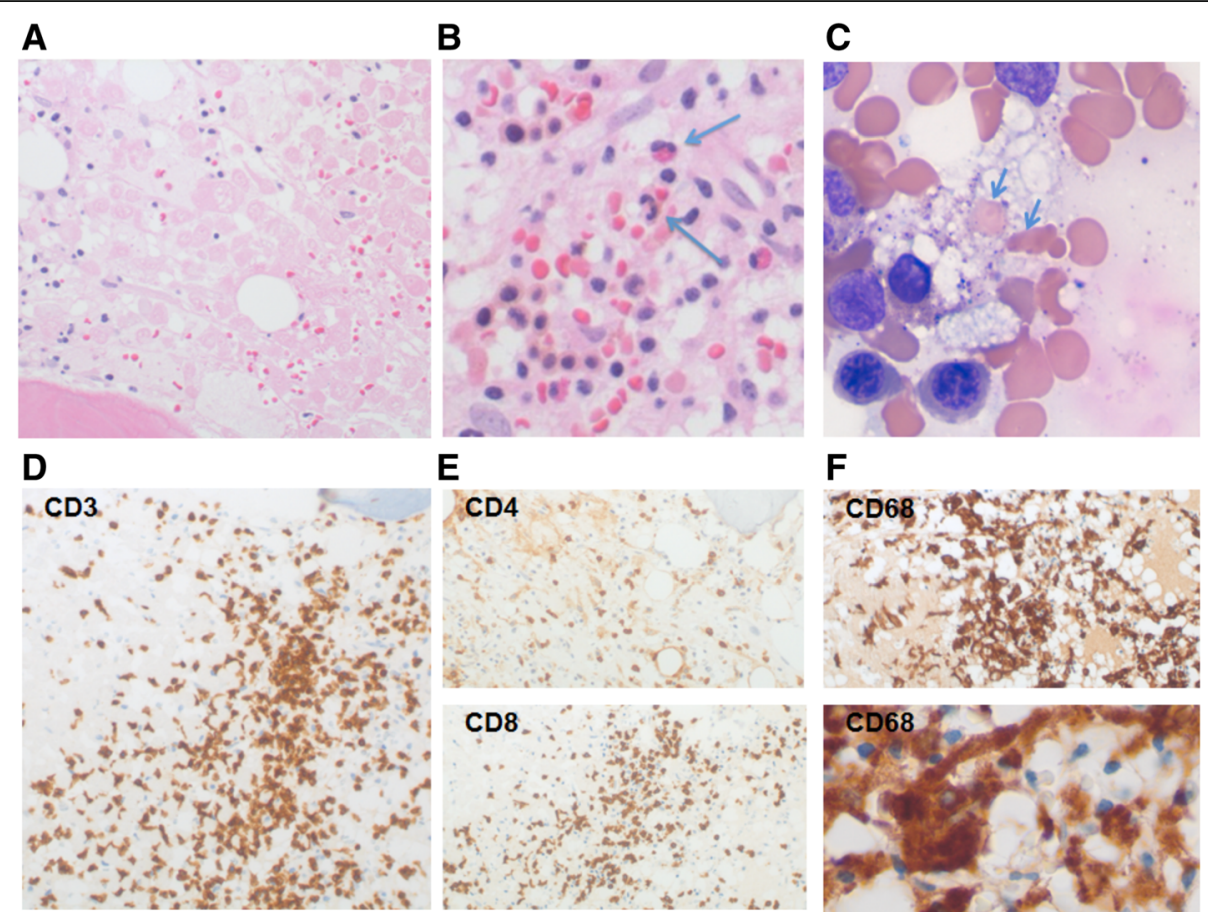

Fig. 2 Bone marrow biopsy obtained at diagnosis. a. Necrotic melanoma cells; H\&E, magnification of 500×. b. Phagocytosing histiocytes containing red blood cells; H\&E, magnification of $500 \times$, blue arrows. c. Phagocytosing histiocytes containing red blood cells, higher magnification. D-F. Immunohistochemistry for CD3 (D), CD8 and CD4 (E), and CD68 (F); magnification of 200x

evidence of involvement by metastatic melanoma (Fig. 3). The patient remains off treatment and in complete remission 12 months later.

\section{Discussion and conclusions}

As anti-CTLA-4 and PD-1 antibodies lead to immune activation, inflammatory effects can occur in any organ system [22]. The majority of patients on single-agent immunotherapy do not experience any side effects and the most common side effects are rash and mild fatigue, likely related to increased circulating cytokines [23]. When specific immune-related toxicity occurs, frequently affected systems include the endocrine organs, gastrointestinal tract, integument, and lungs. Thus, in additional to history and physical exam, thyroid function studies, complete blood counts, and metabolic panels including liver function are generally checked at each treatment and at intervals of 6 to 12 weeks for the first 6 months after finishing treatment, when the risk of toxicity is highest [23, 24]. In patients with non-specific symptoms such as fatigue, evaluation of adrenocorticotropic hormone, cortisol, follicle-stimulating hormone, luteinizing hormone, prolactin, testosterone in men, and estradiol in women is typically pursued. Treatment with corticosteroids regimens, such as intravenous methylprednisolone $1-2 \mathrm{mg} / \mathrm{kg}$ per day for 3-5 days, followed by prednisone, $1-2 \mathrm{mg} / \mathrm{kg}$ per day gradually tapered over 4 weeks can reverse the vast majority of toxic manifestations of these drugs; prolonged tapers are recommended as shorter tapers can lead to a recurrence of symptoms or adrenal crisis [24]. Generally, systemic corticosteroids are used only for grade 3 to 4 or prolonged grade 2 immune-related side effects.

Serious immune-mediated hematologic side effects have also been noted with checkpoint blockade antibodies. Several cases of autoimmune hemolytic anemia have been seen after treatment with nivolumab [25-28]. All of these cases were direct antibody test (DAT) positive for C3 or IgG, did not involve other cytopenias, and most responded to corticosteroids. Pure red cell aplasia has also been seen after treatment with pembrolizumab; while one case of this responded to a prolonged course of corticosteroids, another required further treatments to respond [29, 30]. This second patient developed germinal center-like reactions within the bone marrow that eventually resolved with IVIG followed by the anti-CD20 antibody rituximab [29]. Anti-platelet antibody-positive idiopathic thrombocytopenic purpura has also been seen as a result of anti-PD-1 antibody therapy [31, 32]. In one case, increased PD-1 expression prior to nivolumab treatment was found on the patient's B cells. Treatment of these patients also required intravenous immune globulin and in one case the thrombopoetin analogue 


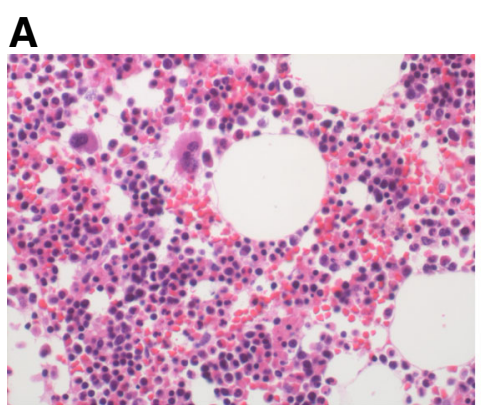

C

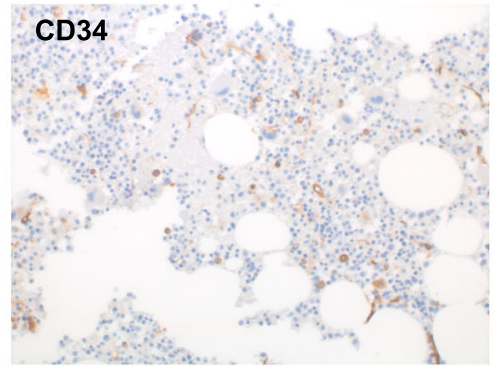

B

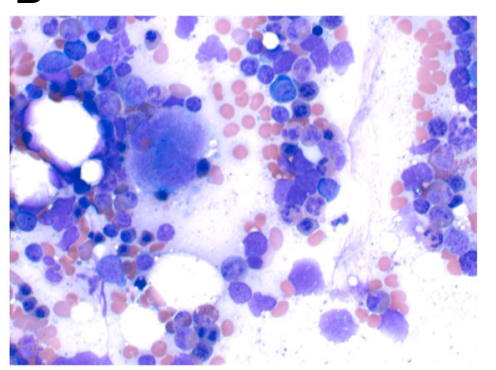

D

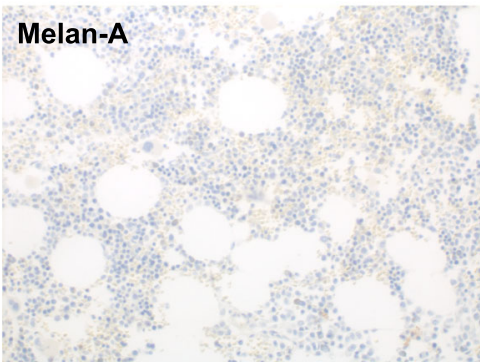

Fig. 3 Bone marrow biopsy obtained after disease resolution. a Regenerative BM core, H\&E, magnification of 500x. b BM aspirate smears showing erythroid hyperplasia with no neoplastic cells. Wright-Giemsa, magnification of 500x. Immunohistochemistry for CD34 (c) and Melan-A (d). There was no increase in CD34 ${ }^{+}$blasts, and no detectable Melan-A-positive cells, i.e. no melanoma; magnification 200x

romiplostin was administered. While not reported with anti-PD-1 antibody therapy, metastatic melanoma patients treated with IL-2 have been observed to develope thrombotic thrombocytopenic purpura, each case requiring cessation of therapy and treatment with plasmapheresis [33]. Many patients in this group of hematologic complications had prior auto-immune like toxicities with therapy, including hepatitis, hypothyroidism, and pneumonitis [24-32]. We are not aware of a previous case of hemophagocytic lymphohistiocytosis reported as a complication of immune therapy for cancer.

Our patient met the criteria for HLH with splenomegaly, cytopenias, hypertriglyceridemia, hemophagocytosis, elevated ferritin, and elevated soluble CD25 levels. Except for her recent treatment with ipilimumab and nivolumab, there was no other obvious or common cause of HLH including fulminant progression of disease or overwhelming infection. Additionally, other similarly presenting diagnoses, including disseminated intravascular coagulation, autoimmune hemolytic anemia, thrombotic thrombocytopenic purpura, or liver failure, were effectively ruled out. Given that the immunologic processes governing both the pathophysiology of HLH and the beneficial effects of checkpoint blockade are similar, future cases of immunotherapy complicated by DAT-negative anemia and low reticulocyte indices should prompt consideration of the HPS syndromes.

Outcomes for the HPS syndromes vary depending on the underlying cause [1]. Given the germline predisposition of
FLH, long-term remission in these patients requires allogeneic stem cell transplantation. Treatment of secondary HLH generally follows the HLH-2004 protocol with etoposide and corticosteroids as well as therapy specific to the underlying disease (antibiotics, additional chemotherapy, etc.) [3]. In our patient, both the significant elevation in bilirubin as well as the excellent response to corticosteroids in immunologic events considered secondary to checkpoint blockade dissuaded us from the use of up-front etoposide. Fortunately, she responded both clinically and by laboratory values to corticosteroids alone and her HLH has not recrudesced to date. If corticosteroids alone were not sufficient, our treatment team would have considered IL-1R antagonist or anti-IL-6 antibodies, which have been used successfully in childhood cases of MAS given the clear immunologic nature of the etiology in the current case.

This is, to our knowledge, the first reported experience of immunotherapy with checkpoint blockade causing hemophagocytic lymphocytosis. The trigger for the syndrome in this case may have been related to rapid tumor cell death and immune activation specifically within the bone marrow compartment, as evidenced by the tumor cell debris along side of $\mathrm{CD}^{+} \mathrm{T}$ cell infiltration and hemophagocytosis seen by bone marrow biopsy. Recently, Gordon et al. published a report demonstrating that tumor-associated macrophages increase over time in mouse and human models of cancer and that PD-1 expression inversely relates to their phagocytic potency against tumor cells [34]. With the addition of blockade 
against PD-1/PDL-1, they showed an increase in macrophage phagocytosis of tumor cells. While this study did not demonstrate increased hemophagocytosis or specific effects on histiocyte activity, it is an intriguing biological rationale for the increased phagocytic activity seen in this case. Future care of cancer patients treated with these agents should consider HLH if similar constellations of symptoms and laboratory values arise.

\section{Acknowledgements}

The authors thank Drs. Jason Luke and Yuanyuan Zha for contributions to biobanking.

\section{Funding}

This work was supported in part by R35CA210098 (TFG).

\section{Availability of data and materials}

All clinical data from this case report is HIPAA-protected patient information and consent has been obtained from the patient for publication, as noted above. There is no other primary data within this submission.

\begin{abstract}
Authors' contributions
$\mathrm{AH}$ wrote and edited the manuscript. GB participated in writing and editing as well as collection of data. JC performed the histologic examination of the bone marrow and provided the figures. HG participated in writing and editing. TG edited and had final editorial control over the manuscript. All authors read and approved the final manuscript.
\end{abstract}

\section{Ethics approval and consent to participate}

Not applicable: this is not a research clinical trial, consent for use and publication of patient data was obtained as below.

\section{Consent for publication}

Patient consent was obtained and can be requested separately as per the submission guidelines.

\section{Competing interests}

TFG has received research funding from Bristol-Myers Squibb, the manufacturer of ipilimumab and nivolumab.

\section{Publisher's Note}

Springer Nature remains neutral with regard to jurisdictional claims in published maps and institutional affiliations.

\section{Author details}

1Department of Medicine, Section of Hematology/Oncology, The University of Chicago, 5841 S. Maryland Ave., MC2115, Chicago, IL 60637, USA. ²Pritzker School of Medicine, The University of Chicago, Chicago, USA. ${ }^{3}$ Department of Pathology, The University of Chicago, Chicago, USA.

Received: 12 March 2018 Accepted: 2 July 2018

Published online: 16 July 2018

\section{References}

1. Hayden A, Park S, Giustini D, Lee AY, Chen LY. Hemophagocytic syndromes (HPSs) including hemophagocytic lymphohistiocytosis (HLH) in adults: a systematic scoping review. Blood Rev. 2016;30(6): 411-20. https://doi.org/10.1016/j.blre.2016.05.001. PubMed PMID: 27238576

2. Jaffe R. The histiocytoses. Clin Lab Med. 1999;19(1):135-55. PubMed PMID: 10403078

3. Henter II, Horne A, Arico M, Egeler RM, Filipovich AH, Imashuku S, et al. HLH-2004: diagnostic and therapeutic guidelines for hemophagocytic lymphohistiocytosis. Pediatr Blood Cancer. 2007;48(2):124-31. https://doi. org/10.1002/pbc.21039. PubMed PMID: 16937360

4. Fukaya S, Yasuda S, Hashimoto T, Oku K, Kataoka H, Horita T, et al. Clinical features of haemophagocytic syndrome in patients with systemic autoimmune diseases: analysis of 30 cases. Rheumatology (Oxford). 2008; 47(11):1686-91. https://doi.org/10.1093/rheumatology/ken342. PubMed PMID: 18782855

5. Bodley Scott RS. A. Histiocytic medullary reticulocytosis. Lancet. 1939; 23(45):19-25.

6. Hadchouel M, Prieur AM, Griscelli C. Acute hemorrhagic, hepatic, and neurologic manifestations in juvenile rheumatoid arthritis: possible relationship to drugs or infection. J Pediatr. 1985;106(4):561-6. PubMed PMID: 3981309

7. Egeler RM, Shapiro R, Loechelt B, Filipovich A. Characteristic immune abnormalities in hemophagocytic lymphohistiocytosis. J Pediatr Hematol Oncol. 1996;18(4):340-5. PubMed PMID: 8888739

8. Stepp SE, Dufourcq-Lagelouse R, Le Deist F, Bhawan S, Certain S, Mathew PA, et al. Perforin gene defects in familial hemophagocytic lymphohistiocytosis. Science. 1999;286(5446):1957-9. PubMed PMID: 10583959

9. Chandrakasan S, Filipovich AH. Hemophagocytic lymphohistiocytosis: advances in pathophysiology, diagnosis, and treatment. J Pediatr. 2013;163(5):1253-9. https://doi.org/10.1016/j.jpeds.2013.06.053. PubMed PMID: 23953723

10. Lykens JE, Terrell CE, Zoller EE, Risma K, Jordan MB. Perforin is a critical physiologic regulator of T-cell activation. Blood. 2011;118(3): 618-26. https://doi.org/10.1182/blood-2010-12-324533. PubMed PMID: 21606480; PubMed Central PMCID: PMCPMC3142903

11. Behrens EM, Canna SW, Slade K, Rao S, Kreiger PA, Paessler M, et al. Repeated TLR9 stimulation results in macrophage activation syndrome-like disease in mice. J Clin Invest. 2011;121(6):2264-77. https://doi.org/10.1172/JCI43157. PubMed PMID: 21576823; PubMed Central PMCID: PMCPMC3104738

12. Henter Jl, Arico M, Egeler RM, Elinder G, Favara BE, Filipovich AH, et al. HLH-94: a treatment protocol for hemophagocytic lymphohistiocytosis. HLH study Group of the Histiocyte Society. Med Pediatr Oncologia. 1997;28(5):342-7. PubMed PMID: 9121398

13. Coit DG, Thompson JA, Algazi A, Andtbacka R, Bichakjian CK, Carson WE 3rd, et al. Melanoma, version 2.2016, NCCN clinical practice guidelines in oncology. J Natl Compr Canc Netw. 2016:14(4):450-73. PubMed PMID: 27059193

14. Buchbinder El, Desai A. CTLA-4 and PD-1 pathways: similarities, differences, and implications of their inhibition. Am J Clin Oncol. 2016;39(1):98-106. https://doi.org/10.1097/COC.0000000000000239. PubMed PMID: 26558876; PubMed Central PMCID: PMCPMC4892769

15. Khalil DN, Budhu S, Gasmi B, Zappasodi R, Hirschhorn-Cymerman D, Plitt $T$, et al. The new era of Cancer immunotherapy: Manipulating TCell Activity to Overcome Malignancy. Adv Cancer Res. 2015;128:1-68. https://doi.org/10.1016/bs.acr.2015.04.010. PubMed PMID: 26216629

16. Boussiotis VA. Molecular and Biochemical aspects of the PD-1 checkpoint pathway. N Engl J Med. 2016;375(18):1767-78. https://doi. org/10.1056/NEJMra1514296. PubMed PMID: 27806234; PubMed Central PMCID: PMCPMC5575761

17. Hodi FS, O'Day SJ, McDermott DF, Weber RW, Sosman JA, Haanen JB, et al. Improved survival with ipilimumab in patients with metastatic melanoma. N Engl J Med. 2010;363(8):711-23. https://doi.org/10.1056/NEJMoa1003466. PubMed PMID: 20525992; PubMed Central PMCID: PMCPMC3549297

18. Robert C, Long GV, Brady B, Dutriaux C, Maio M, Mortier L, et al. Nivolumab in previously untreated melanoma without BRAF mutation. N Engl J Med. 2015;372(4):320-30. https://doi.org/10.1056/ NEJMoa1412082. PubMed PMID: 25399552

19. Schachter J, Ribas A, Long GV, Arance A, Grob JJ, Mortier L, et al. Pembrolizumab versus ipilimumab for advanced melanoma: final overall survival results of a multicentre, randomised, open-label phase 3 study (KEYNOTE-006). Lancet. 2017;390(10105):1853-62. https://doi.org/10.1016/ S0140-6736(17)31601-X. PubMed PMID: 28822576

20. Wolchok JD, Chiarion-Sileni V, Gonzalez R, Rutkowski P, Grob JJ, Cowey $\mathrm{CL}$, et al. Overall survival with combined Nivolumab and Ipilimumab in advanced melanoma. N Engl J Med. 2017;377(14):134556. https://doi.org/10.1056/NEJMoa1709684. PubMed PMID: 28889792; PubMed Central PMCID: PMCPMC5706778

21. Larkin J, Chiarion-Sileni V, Gonzalez R, Grob JJ, Cowey CL, Lao CD, et al. Combined Nivolumab and Ipilimumab or monotherapy in untreated melanoma. N Engl J Med. 2015:373(1):23-34. https://doi. org/10.1056/NEJMoa1504030. PubMed PMID: 26027431 
22. Postow MA. Managing immune checkpoint-blocking antibody side effects. Am Soc Clin Oncol Educ Book. 2015:76-83. https://doi.org/10.14694/ EdBook_AM.2015.35.76. PubMed PMID: 25993145

23. Friedman CF, Proverbs-Singh TA, Postow MA. Treatment of the immunerelated adverse effects of immune checkpoint inhibitors: a review. JAMA Oncol. 2016;2(10):1346-53. https://doi.org/10.1001/jamaoncol.2016.1051. PubMed PMID: 27367787

24. Gonzalez-Rodriguez E, Rodriguez-Abreu D. Spanish Group for Cancer I-B. Immune checkpoint inhibitors: review and management of endocrine adverse events. Oncologist. 2016;21 (7):804-16. https://doi.org/10.1634/ theoncologist.2015-0509. PubMed PMID: 27306911; PubMed Central PMCID: PMCPMC4943391

25. Tardy MP, Gastaud L, Boscagli A, Peyrade F, Gallamini A, Thyss A. Autoimmune hemolytic anemia after nivolumab treatment in Hodgkin lymphoma responsive to immunosuppressive treatment. A case report. Hematol Oncol. 2017;35(4):875-7. https://doi.org/10.1002/hon.2338. PubMed PMID: 27539158

26. Kong BY, Micklethwaite KP, Swaminathan S, Kefford RF, Carlino MS. Autoimmune hemolytic anemia induced by anti-PD-1 therapy in metastatic melanoma. Melanoma Res. 2016;26(2):202-4. https://doi.org/10.1097/CMR. 0000000000000232. PubMed PMID: 26795275

27. Palla AR, Kennedy D, Mosharraf H, Doll D. Autoimmune hemolytic Anemia as a complication of Nivolumab therapy. Case Rep Oncol. 2016;9(3):691-7. https://doi.org/10.1159/000452296. PubMed PMID: 27920704; PubMed Central PMCID: PMCPMC5126613

28. Schwab KS, Heine A, Weimann T, Kristiansen G, Brossart P. Development of hemolytic Anemia in a Nivolumab-treated patient with refractory metastatic squamous cell skin Cancer and chronic lymphatic leukemia. Case Rep Oncol. 2016;9(2):373-8. https://doi.org/10.1159/000447508. PubMed PMID: 27462240; PubMed Central PMCID: PMCPMC4939691

29. Gordon IO, Wade T, Chin K, Dickstein J, Gajewski TF. Immune-mediated red cell aplasia after anti-CTLA-4 immunotherapy for metastatic melanoma. Cancer Immunol Immunother. 2009;58(8):1351-3. https://doi.org/10.1007/ s00262-008-0627-x. PubMed PMID: 19052742

30. Nair R, Gheith S, Nair SG. Immunotherapy-associated hemolytic Anemia with pure red-cell aplasia. N Engl J Med. 2016;374(11):1096-7. https://doi.org/10. 1056/NEJMc1509362. PubMed PMID: 26981948

31. Kanameishi S, Otsuka A, Nonomura Y, Fujisawa A, Endo Y, Kabashima K. Idiopathic thrombocytopenic purpura induced by nivolumab in a metastatic melanoma patient with elevated PD-1 expression on B cells. Ann Oncol. 2016;27(3):546-7. https://doi.org/10.1093/annonc/mdv580. PubMed PMID: 26602778

32. Le Roy A, Kempf E, Ackermann F, Routier E, Robert C, Turpin A, et al. Two cases of immune thrombocytopenia associated with pembrolizumab. Eur J Cancer. 2016;54:172-4. https://doi.org/10.1016/j.ejca.2015.10.073. PubMed PMID: 26687374

33. Alexandrescu DT, Maddukuri P, Wiernik PH, Dutcher JP. Thrombotic thrombocytopenic purpura/hemolytic uremic syndrome associated with high-dose interleukin-2 for the treatment of metastatic melanoma. J Immunother. 2005;28(2):144-7. PubMed PMID: 15725958

34. Gordon SR, Maute RL, Dulken BW, Hutter G, George BM, McCracken MN, et al. PD-1 expression by tumour-associated macrophages inhibits phagocytosis and tumour immunity. Nature. 2017;545(7655):495-9. https:// doi.org/10.1038/nature22396. PubMed PMID: 28514441; PubMed Central PMCID: PMCPMC5931375

\section{Ready to submit your research? Choose BMC and benefit from:}

- fast, convenient online submission

- thorough peer review by experienced researchers in your field

- rapid publication on acceptance

- support for research data, including large and complex data types

- gold Open Access which fosters wider collaboration and increased citations

- maximum visibility for your research: over $100 \mathrm{M}$ website views per year

At BMC, research is always in progress.

Learn more biomedcentral.com/submissions 